\title{
Downregulation of gastrokine-1 in gastric cancer tissues and restoration of its expression induced gastric cancer cells to apoptosis
}

Wei Mao ${ }^{1,2+}$, Jie Chen ${ }^{1 \dagger}$, Tie-Li Peng ${ }^{1}$, Xiao-Fei Yin ${ }^{1}$, Lian-Zhou Chen ${ }^{3}$ and Min-Hu Chen ${ }^{1 *}$

\begin{abstract}
Background: Gastrokine-1 (GKN1), a secreted protein, is specifically expressed in gastric mucosa to protect and maintain the integrity of gastric epithelium. The present study investigated differential expression of GKN1 in normal, precancerous, and cancerous gastric tissues, and explored the biological functions of GKN1 protein in gastric cancer cells.
\end{abstract}

Methods: RT-PCR, Western blot, and immunohistochemistry were performed to detect GKN1 expression in normal, precancerous, cancerous gastric tissues and seven gastric cancer cell lines. Gene transfection was used to restore GKN1 expression in gastric cancer AGS cells. Phenotypic changes (i.e., cell viability, apoptosis, cell cycle modulation, and sensitivity of gastric cancer cells to fluorouracil (5-FU)) were assayed in the transfected cells. DNA microarrays were used to analyze expression changes of apoptosis-related genes.

Results: Significant downregulation or absence of GKN1 expression in seven gastric cancer cell lines were detected and progressive decrease of GKN1 expression from normal mucosa, precancerous tissue, to cancer tissues was observed. Moreover, restoration of GKN1 expression suppressed gastric cancer cell viability and induced the cells to undergo apoptosis. GKN1 expression also enhanced tumor cell sensitivity to 5-FU treatment. Moreover, it was found that GKN1 expression in AGS cells modulated expression of 19 apoptosis-related genes.

Conclusions: Expression of GKN1 is progressively lost from normal mucosa, precancerous to cancerous gastric tissues, while restoration of GKN1 expression induces gastric cancer cells to undergo apoptosis, and enhances sensitivity of gastric cancer cells to 5-FU-induced apoptosis.

Keywords: Gastrokine-1, Gastric cancer, Immunohistochemistry, Cell viability, Apoptosis, 5-FU

\section{Background}

Gastric cancer is the fourth most common cancer, and one of the leading causes of cancer-related deaths in the world [1-3]. Although there have been a number of recent research advances in gastric cancer, such as improvements in early detection, advances in molecular research, newer surgery techniques, and more chemotherapy options, the overall survival rate for patients with gastric cancer has not been significantly improved. Therefore, research that focuses on new biological

\footnotetext{
* Correspondence: chenminhu@vip.163.com

${ }^{\dagger}$ Equal contributors

'Department of Gastroenterology, the First Affiliated Hospital of Sun Yat-Sen University, Guangzhou, China

Full list of author information is available at the end of the article
}

markers of early detection, new agents of possible genetic target, and further elucidating the molecular mechanisms will contribute to the therapeutic strategies.

Gastrokine-1 (GKN1), a novel protein cloned by a Japanese group in 2000 [4], is exclusively expressed in the gastric epithelium and easily biopsied. During gastric carcinogenesis, the GKN1 protein is downregulated in comparison to abundant expression in normal gastric mucosa [5]. Thus, this protein may be a potential biological marker for early detection of gastric cancer. Functionally, GKN1 promotes the maturation of gastric mucosa, and maintains the integrity of gastric mucosal epithelium through mitogenic and mutagenic abilities [6]. GKN1 may also protect the intestinal mucosal barrier by acting on specific tight junction proteins and

\section{Ciomed Central}


stabilizing perijunctional actin [7]. Molecularly, the GKN1 protein contains a BRICHOS domain, which is associated with dementia, respiratory distress and cancer [8]. Therefore, the deficiency of GKN1 will result in the instability of gastric mucosa. The risk factors such as H. pylori can contribute to the down regulation of GKN1; meanwhile induce ulceration and cancer $[9,10]$. In addition, several studies observed that GKN1 expression was down regulation in gastric atrophy and intestinal metaplastic lesions and even absence in gastric cancer [5,11]. These studies demonstrate that GKN1 may play a key role in the gastric cancer progression.

In the present study, we examined GKN1 expression in tissue specimens of normal, premalignant, and malignant gastric mucosa. We then investigated the possible biological functions of GKN1 in gastric cancer cells by assessing the resulting phenotypic changes in GKN1 transfected cells. The primary aim of this study was to identify and characterize GKN1 as a potential tumor suppressor in gastric cancer.

\section{Methods}

\section{Tissue specimens}

Tissue specimens of atrophic gastritis, intestinal metaplasia, dysplasia, and gastric cancer were obtained from a total of 159 patients in our university hospitals. The premalignant lesions were from patients who underwent upper gastrointestinal endoscopy. Tissues of gastric tumors and their corresponding distant non-tumor tissues were collected from 39 gastric cancer patients who underwent surgery (Table 1). None of the gastric cancer patients received preoperative chemotherapy or radiotherapy. In addition, 20 healthy volunteers were also obtained for this study and these individuals visited our hospital for routine physical examinations and were confirmed to be negative for $H$. pylori infection by using ${ }^{13} \mathrm{C}$-urea breath test. All participants signed a written informed consent, and our Institutional Review Board approved the work. All tissue specimens were histologically re-confirmed by pathologists [12].

Table 1 Clinic and histological characteristics of the study population

\begin{tabular}{|c|c|c|c|c|}
\hline \multirow[t]{2}{*}{ Histological type } & \multirow{2}{*}{$\begin{array}{l}\text { Patient } \\
\text { number }\end{array}$} & \multicolumn{2}{|c|}{ Gender } & \multirow{2}{*}{$\begin{array}{l}\text { Age }(y r) \\
\text { mean } \pm S D\end{array}$} \\
\hline & & Male & Female & \\
\hline Healthy volunteers & 20 & 10 & 10 & $44.6 \pm 12.7$ \\
\hline Atrophic gastritis & 40 & 25 & 15 & $50.2 \pm 10.8$ \\
\hline Intestinal metaplasia & 40 & 26 & 14 & $60.9 \pm 13.5$ \\
\hline Dysplasia & 40 & 30 & 10 & $64.0 \pm 11.4$ \\
\hline Gastric cancer & 39 & 23 & 16 & $53.0 \pm 10.0$ \\
\hline
\end{tabular}

\section{Gastric cancer cell lines}

Seven gastric cancer cell lines, MKN28, MKN45, AGS, N87, SNU 1, SNU 16 and KATO, were obtained from the Riken Cell Bank (Tsukuba, Japan) or the American Type Culture Collection (Manassas, VA, USA). Cells were cultured in RPMI 1640 medium containing 10\% fetal bovine serum (Hyclone, Logan, USA), and maintained at $37^{\circ} \mathrm{C}$ in a humidified $5 \% \mathrm{CO}_{2}$ atmosphere.

\section{RNA isolation and RT-PCR}

Gastric tissue specimens were homogenized with an ultrasound homogenizer. Total RNA from tissues and tumor cells was isolated using the Qiagen RNeasy Mini Kit (Qiagen, Hilden, Germany) according to the manufacturer's instructions. After quantification, RNA was reverse transcribed into cDNA using ReverTra $\mathrm{Ace}^{\mathrm{m}}$ Kit (Toyobo Co., Osaka, Japan). The newly synthesized cDNA was then amplified by PCR with specific primers for the GKN1 gene (5'-TTTGCTGGACTTCTTGGA-3' and $5^{\prime}$-TCGACTTTGTTTGGGTTG-3/) or $\beta$-actin, which was used as an internal control. PCR amplification was performed under the following conditions: an initial cycle at $94^{\circ} \mathrm{C}$ for $5 \mathrm{~min}$, followed by 28 cycles at $94^{\circ} \mathrm{C}$ for $45 \mathrm{sec}, 53^{\circ} \mathrm{C}$ for $30 \mathrm{sec}$, and $72^{\circ} \mathrm{C}$ for $1 \mathrm{~min}$, with a final extension at $72^{\circ} \mathrm{C}$ for $7 \mathrm{~min}$. PCR products were subsequently electrophoresed on a $1.5 \%$ agarose gel, and visualized under a UV transilluminator.

\section{Protein extraction and Western blot}

Total cellular protein was extracted from tissue specimens and gastric cancer cells, using a lysis buffer containing a $1 \mathrm{X}$ protease inhibitor cocktail (Roche, Mannheim, Germany). Protein was quantified using the BCA Protein Assay Kit (Pierce Biotechnology, Rockford, USA). Equal amounts of protein were resolved by $10 \%$ SDS-PAGE, and electroblotted onto polyvinylidene difluoride (PVDF) membranes. Membranes were then blocked in 5\% non-fat milk overnight, and the next day, were incubated for $2 \mathrm{~h}$ with a 1:500 dilution of antiGKN1 antibody (Abnova, Taipei, China) or a 1:1000 dilution of an antibody against beta-actin (Cell Signaling Technology, Danvers, USA,). After washed with phosphate buffered saline (PBS) three times and incubation for $1 \mathrm{~h}$ with the appropriate secondary antibody, enhanced chemiluminescence (Pierce Biotechnology, Rockford, USA) was used for protein visualization.

\section{Immunohistochemistry}

Paraffin sections ( $4 \mu \mathrm{m}$ thick) were prepared, deparaffinized in xylene, and then hydrated through graded series of ethanol concentrations. Antigen retrieval was performed by heating the sections for $10 \mathrm{~min}$ at $100^{\circ} \mathrm{C}$ in $0.01 \mathrm{M}$ citrate buffer ( $\mathrm{pH}$ 6.0), endogenous peroxidase activity was quenched with $3 \% \mathrm{H}_{2} \mathrm{O}_{2}$ for $15 \mathrm{~min}$, and 
nonspecific staining was reduced by incubating with a blocking serum for $10 \mathrm{~min}$. The sections were then incubated with mouse anti-human GKN1 (1:300, Abnova) at room temperature for $2 \mathrm{~h}$. Then, a 2-step detection method was used according to the manufacturer's instructions (EnVision ${ }^{\mathrm{TM}}$ Detection Kit, Gene Tech Co., China) by incubation of the tissue with the ChemMate ${ }^{\text {TM }}$ EnVision $^{\mathrm{TM}} / \mathrm{HRP}$ for $30 \mathrm{~min}$ at room temperature. The reaction was visualized by the CheMate ${ }^{\mathrm{Ts}}$ DAB plus Chromogen. Lastly, the sections were counterstained with hematoxylin solution. Negative controls were performed by staining with primary antibody.

The stained sections were evaluated and scored for staining intensity and $\%$ of staining under a light microscope, i.e., percentage of staining was documented as 0 (<5\%), 1 (5\%-25\%), 2 (26\%-50\%), 3 (51\%-75\%), and 4 $(>75 \%)$. Staining intensity was documented as 0 (no immunostaining), 1 (weak), 2 (moderate), and 3 (strong). The value of these two scores were added together to garner a final score for each case: a scale of 0 (score less than 2), $1+$ (score range from 2 to 3 ), 2+ (score range from 4 to 5 ), and $3+$ (score range from 6 to 7 ). Immunostaining was assessed by an experienced pathologist who was blinded to the clinical data of the patients.

\section{Construction of GKN1 expression vector for gene transfection}

GKN1 cDNA was amplified from total RNA of the normal gastric mucosa using PCR. GKN1 CDS fragments with SalI and BamHI restriction sites were then inserted into the pBudCE4.1 vector (Invitrogen, Carlsbad, CA, USA) using a DNA ligation kit from TaKaRa (Dalian, China). After transformation into DH5 $\alpha$ E. Coli competent cells, the plasmid was amplified and the DNA sequence was then confirmed. To generate gastric cancer cells expressing GKN1, gastric cancer AGS cells were grown to $50-75 \%$ confluency in a six-well plate, washed twice with RPMI lacking supplements (RPMS/LS), and subjected to the Lipofectamine-mediated transfection according to the manufacturer's protocol (Invitrogen). The GKN1 transfected gastric cancer cells were then selected in medium containing Zeocin (Invitrogen). After the transfected cells formed individual cell colonies, stable cells were obtained and then confirmed for GKN1 expression by using RT-PCR and Western blot analyses.

\section{Cell viability (MTT) assay}

To detect changes in tumor cell viability after GKN1 transfection, a total of $1 \times 10^{4}$ trypsin-dispersed cells in $0.1 \mathrm{~mL}$ culture medium was seeded into each well of a 96-well plate, and cultured for $24 \mathrm{~h}$ or $48 \mathrm{~h}$. Next, $20 \mu \mathrm{L}$ of MTT ( $5 \mathrm{~g} / \mathrm{L}$ from Sigma-Aldrich, St. Louis, USA) was added to each well and incubated for additional $4 \mathrm{~h}$ at $37^{\circ} \mathrm{C}$. Culture medium was then replaced with $200 \mu \mathrm{L}$ of dimethyl sulfoxide (DMSO) and the absorbance rate was determined using an ELISA reader at $490 \mathrm{~nm}$. Cell growth inhibition rate was calculated as (the value of experimental group OD/the value of control group OD) $\times 100 \%$.

\section{Annexin $\mathbf{V}$ apoptosis assay}

To detect tumor cell apoptosis, the GKN1 transfected tumor cells were seeded into $60-\mathrm{mm}$ diameter culture plates, and cultured for $24 \mathrm{~h}$ and $48 \mathrm{~h}$. The apoptotic rates were analyzed by flow cytometry using an annexin V-FITC/PI kit. Staining was performed according to the manufacturer's instructions, and flow cytometry was conducted with a flow cytometer (Beckman-Coulter, Brea, USA). Cells with annexin V (-) and PI (-) were deemed viable cells. Cells with annexin $\mathrm{V}(+)$ and PI $(-)$ were deemed early apoptotic cells. Cells with both annexin $\mathrm{V}(+)$ and PI (+) were deemed late apoptotic cells.

\section{TUNEL assay}

To identify apoptosis in the transfected cells, we utilized the dead-end colorimetric TUNEL system kit (Promega, Madison, USA) to measure DNA fragmentation and caspase-3 activation in the GKN1 transfected cells, according to the manufacturer's instructions. Briefly, cells were fixed in $4 \%$ paraformaldehyde solution for $25 \mathrm{~min}$ at room temperature, rinsed in PBS, and permeabilized by incubating the slides in $0.2 \%$ Triton X-100 solution. Cells were then incubated with a terminal deoxynucleotidyl transferase $(\mathrm{TdT})$ reaction mixture containing biotinylated nucleotides and $\mathrm{TdT}$ at $37^{\circ} \mathrm{C}$ for $60 \mathrm{~min}$, and rinsed with $1 \times \mathrm{SSC}$ (sodium chloridesodium citrate buffer) and PBS. Next, streptavidin HRP was added to the cells, and the cell slides were stained with 3,3/-diaminobenzidine color solution. Finally, cells were examined under a light microscope and the number of positive cells was counted and summarized from a total of 10 high power fields.

\section{Cell cycle analysis}

To analyze cell cycle distribution, transfected cells were grown and treated with $25 \mathrm{M}$ olomoucine (Santa Cruz Biotechnologies, Santa Cruz, USA) for $1 \mathrm{~h}$, and then incubated with regular culture medium for an additional $1 \mathrm{~h}$ [13]. Cells were then collected and subjected to cell cycle analysis by flow cytometry as described in the previous section.

\section{Sensitivity to 5-FU treatment}

To detect the role of GKN1 in mediating sensitivity of gastric cancer cells to 5-FU treatment, we grew and treated GKN1 transfected tumor cells with 5-FU (Sigma) or DMSO for $24 \mathrm{~h}$ and $48 \mathrm{~h}$. Concentrations of 5-FU ranged from 


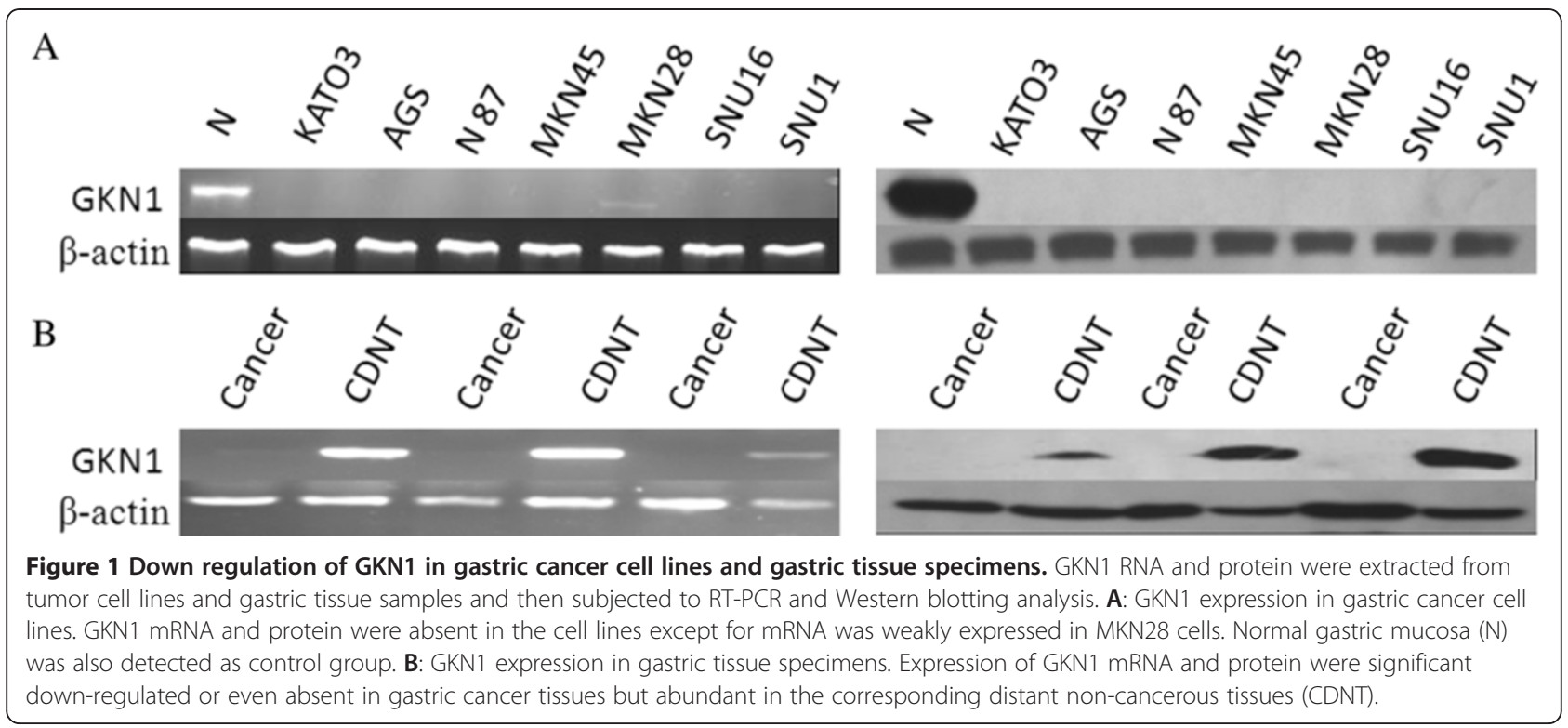

0.25 to $1.0 \mathrm{mmol} / \mathrm{L}$. The apoptosis rate from these cells was detected by flow cytometry as previously described.

\section{cDNA microarray analysis}

To perform cDNA microarray analysis, total cellular RNA from GKN1-transfected and vector-control tumor cells were isolated with the Trizol ${ }^{\circledR}$ Reagent (Invitrogen). RNA was then reversely transcribed into cDNA using the TrueLabeling-AMP Linear RNA amplification kit (Superarray, Frederick, MD, USA), and then converted into biotin-labeled cRNA using biotin-16-UTP and an in vitro transcription kit (Roche, Basel, Switzerland). The newly synthesized cRNA probes were then purified with the ArrayGrade cRNA cleanup kit (Superarray) and then added to the pretreated Oligo GEArrays Human Apoptosis Microarray (OHS-012 from Superarray) that contains 112 apoptosis-related genes. The microarray was then hybridized overnight at $42^{\circ} \mathrm{C}$. The next day, the hybridized arrays were washed and detected by chemiluminescence according to the manufacturer's instructions (Pierce). The data were analyzed using GEArray Expression Analysis software (Superarray). If spot intensity increased by more

Table 2 GKN1 expression detected by immunohistochemistry in gastric tissues

\begin{tabular}{lllllll}
\hline Histological type & Number of patient & - & + & ++ & +++ & $\mathbf{P}$ value \\
\hline Normal gastric mucosa & 20 & 0 & 0 & 0 & 20 & $<0.05$ \\
Atrophic gastritis & 40 & 0 & 15 & 20 & 5 & \\
Intestinal metaplasia & 40 & 21 & 19 & 0 & 0 & \\
Dysplastic lesion & 40 & 26 & 14 & 0 & 0 & \\
Gastric cancer & 39 & 34 & 5 & 0 & 0 & \\
\hline
\end{tabular}

${ }^{1}$ Comparison between healthy volunteers, atrophic gastritis, intestinal metaplasia, dysplasia and gastric cancer tissues, $\mathrm{P}<0.05$. than two fold, this gene was deemed upregulated. In contrast, if spot intensity decreased by more than two fold, the gene was deemed downregulated.

\section{Statistical analysis}

All quantitative data were expressed as mean \pm SD and analyzed using Student $t$-tests. The differential expression of GKN1 among different groups was determined by Kruskal-Wallis test. All statistical analyses were performed using the SPSS statistical software package (version 11.0, SPSS Inc. Chicago, USA). A $P$ value of $<0.05$ was considered statistically significant.

\section{Results}

Expression of GKN1 in cancer cell lines and gastric tissue specimens

We first performed RT-PCR and immunoblot analysis to detect expression of GKN1 mRNA and protein levels in cancer cell lines and tissue specimens. We found that GKN1 mRNA was weakly expressed in gastric cancer MKN 28 cells, and was absence in AGS, N87, MKN45, SNU16, SNU1, and KATO cells (Figure 1A). The GKN1 protein was also not detectable in any of the seven cell lines (Figure 1A). In contrast, GKN1 mRNA and protein were abundance in normal gastric epithelial cells that were obtained from healthy volunteers (Figure 1B). In 39 gastric cancer tissues, GKN1 mRNA was only weakly expressed in 3 tissues, and absence in the remaining 36 tissues. GKN1 protein was weakly expressed in 2 gastric cancer tissues, and absence in the remaining 37 tissues. However, GKN1 mRNA and protein were abundantly expressed in all of the 39 corresponding distant noncancerous tissues (Figure 1B). 


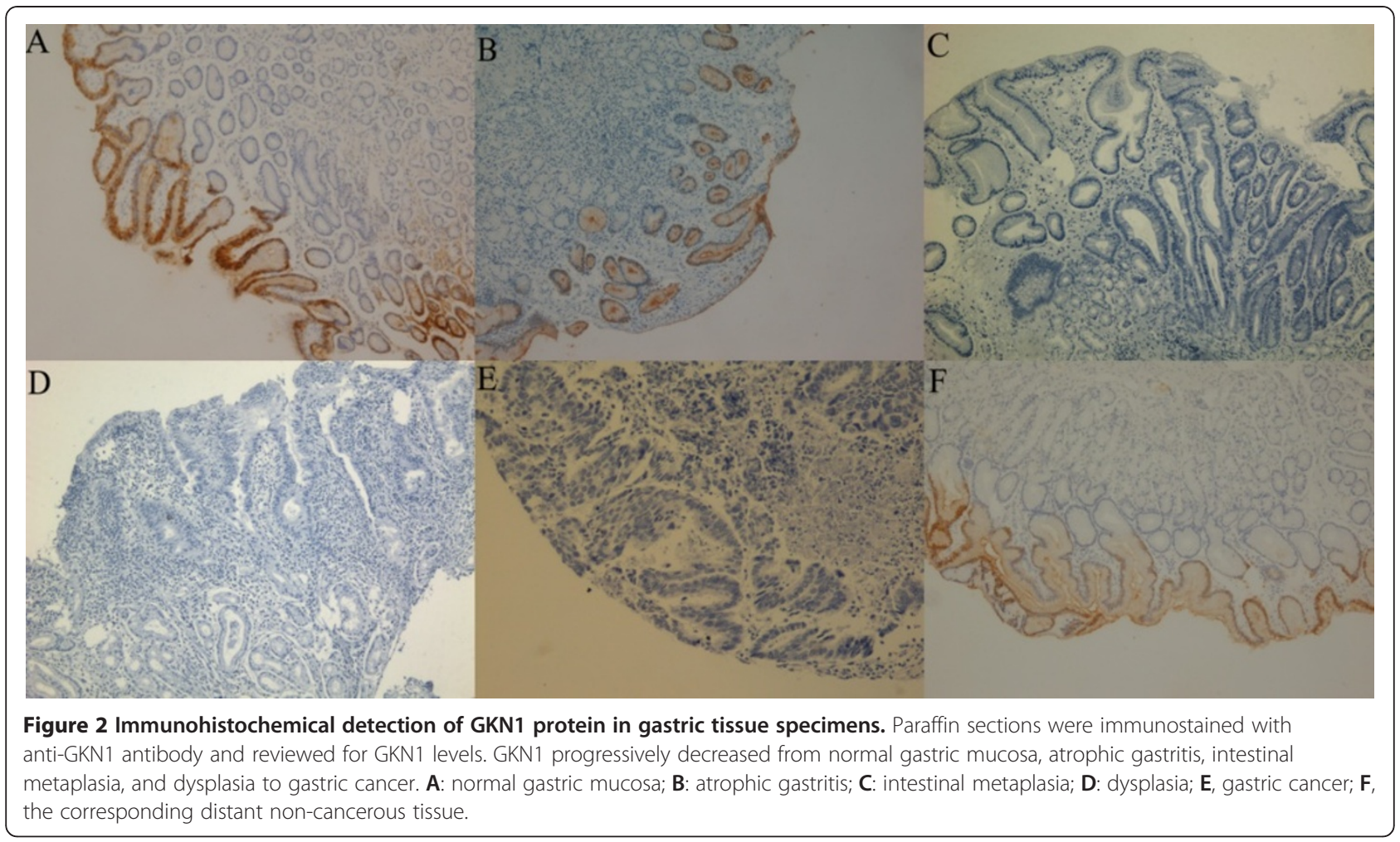

Next, we immunohistochemically stained GKN1 in the tissue sections of normal gastric mucosae (from healthy volunteers), atrophic gastritis, intestinal metaplasia, dysplasia, and gastric cancer and their corresponding distant non-cancerous mucosae. We found that the GKN1 protein was abundantly expressed in the upper glandular layer of the top one third superficial epithelium, while expression of GKN1 protein was progressively down regulated from normal gastric mucosa, atrophic gastritis, intestinal metaplasia and dysplasia, to gastric cancer

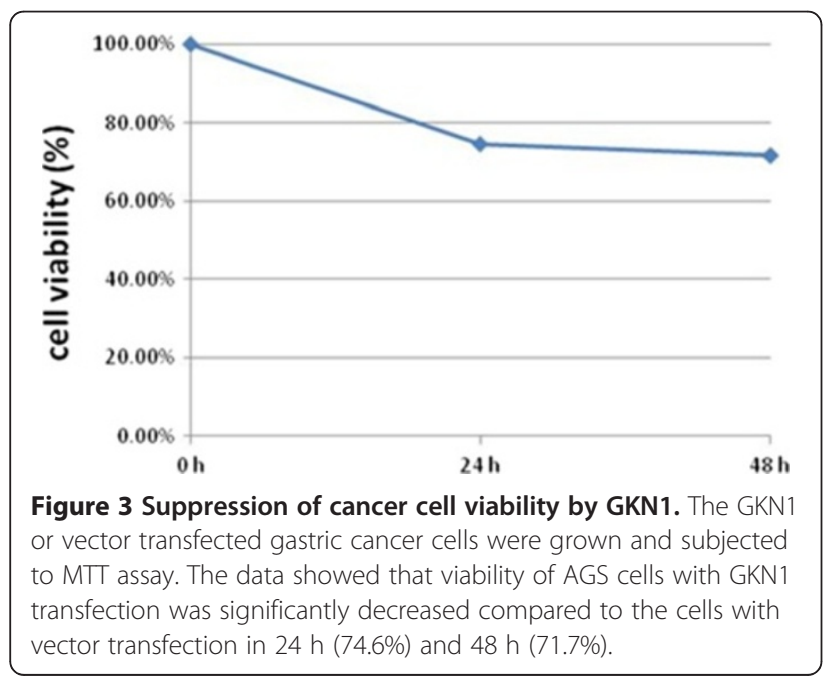

(Table 2) (Figure 2). This reduction in expression was statistically significant $(\mathrm{p}<0.05)$.

\section{Transfection of GKN1 reduced gastric cell proliferation}

Next, we determined whether restoration of GKN1 expression would suppress gastric cancer AGS cells viability. To this end, we generated AGS cells that stably expressed GKN1 expression was confirmed by RT-PCR and Weston blotting. Cell viability (MTT) assays showed that AGS cells stably expressing GKN1 grew at a much slower rate compared to the vector-transfected control cells in both 24 hour and 48 hour cultures (Figure 3). This data clearly indicate that restoration of GKN1 expression inhibits AGS cell proliferation.

\section{Effect of GKN1 on AGS cell apoptosis and cell cycle re-distribution}

We examined whether inhibition of cell proliferation by GKN1 was due to the induction of apoptosis. To this end, we examined the levels of apoptotic cells using flow cytometry, and found that compared to the vector transfected cells, GKN1 transfected AGS cells were apoptotic (Figure 4A). The TUNEL assay demonstrated that endogenous GKN1 significantly induced apoptosis in AGS cells, and examination of morphology demonstrated that the nuclei of GKN1 transfected tumor cells exhibited condensation and fragmentation (Figure 4B). 


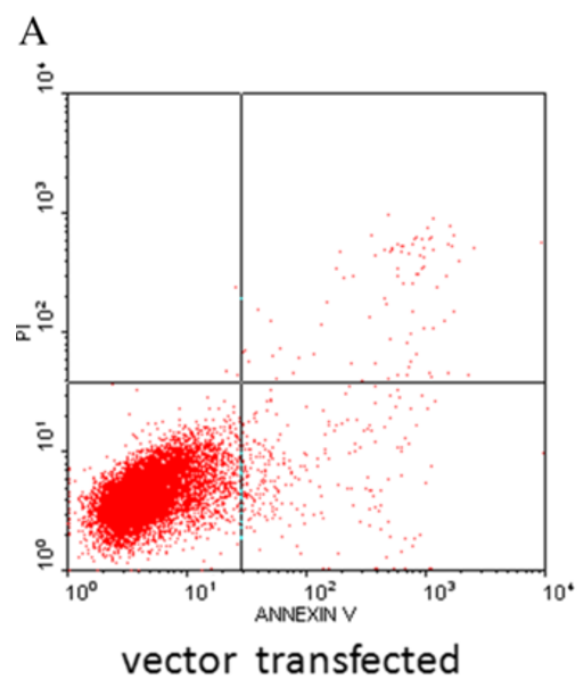

$\mathrm{B}$
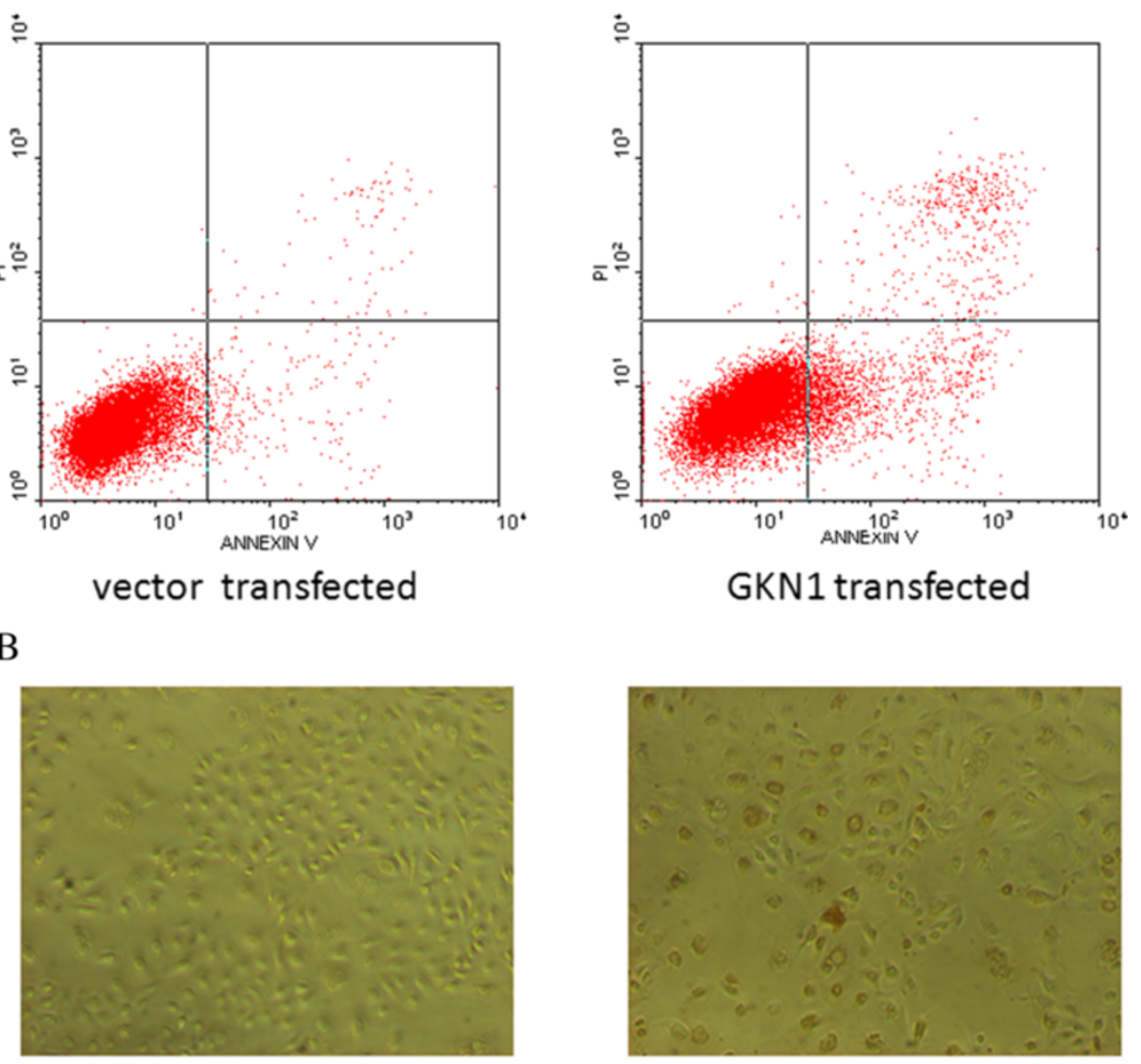

vector transfected

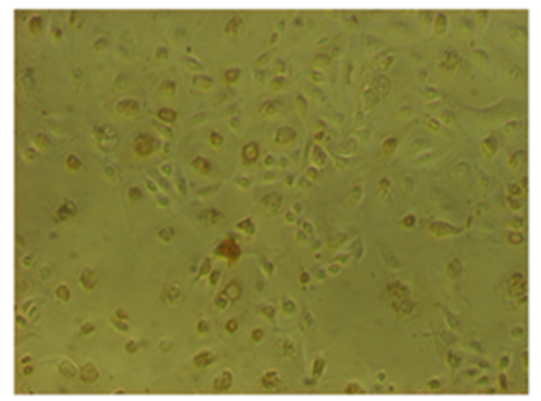

GKN1 transfected

Figure 4 Apoptosis induction of gastric cancer cell by GKN1. A: Flow cytometric assay. The GKN1 or vector transfected gastric cancer AGS cells were grown and subjected to flow cytometry assay for detection of apoptosis; B: TUNEL assay. The GKN1 or vector transfected gastric cancer cells were grown on glass slides and then subjected to TUNEL assay.

Next, we examined cell cycle changes in these tumor cells, because suppression of cell viability is closely related to regulation of the cell cycle. Olomoucine, a purine derivative, is a cyclin-dependent kinase (CDK) inhibitor, thus we used it to enrich parental AGS cells in the G1 phase. Specifically, cells were arrested in the cell cycle with $1 \mathrm{~h}$ olomoucine treatment and continued to incubate for another $1 \mathrm{~h}$ without olomoucine. The cell cycle distribution of GKN1 transfected cells changed from $41.9 \%$ of G1 and $35.0 \%$ of S phase to $41.2 \%$ of $\mathrm{G} 1$ and $28.7 \%$ of $\mathrm{S}$ phase of the cell cycles. Similarly, the cell cycle distribution of vectortransfected cells changed from $47.2 \%$ G1 and $29.1 \%$ of S phase to $44.1 \% \mathrm{G} 1$ and $25.3 \%$ of $\mathrm{S}$ phase of the cell cycles (Figure 5). These data demonstrate that GKN1 is unable to arrest AGS cells in the G1-S transition phase of cells.

\section{GKN1 enhanced tumor cell sensitivity to 5-FU mediated apoptosis}

Clinically, 5-FU is routinely used in the treatment of gastric cancer. In this study, we assessed whether presence of GKN1 could enhance sensitivity of gastric cancer cells to 5-FU treatment. Flow cytometry was used to detect apoptosis rate after 24 hours and 48 hours (Table 3 ) with different concentrations of 5-FU in the GKN1 transfected cells. The results showed that apoptosis was significantly induced in GKN1 transfected cells, in a time and dose-dependent manner, compared to the vector transfected cells (Table 3; Figure 6).

\section{GKN1 modulation of apoptosis-related gene expression}

So far, we had demonstrated that GKN1 expression was able to induce apoptosis in gastric cancer cells. We therefore profiled the expression change of apoptosis-related genes in GKN1 transfected and vector transfected AGS cells by cDNA microarray. The Oligo GEArray-Human Apoptosis Microarray (OHS012 from Superarray) contains 112 apoptosis-related genes. After hybridization of RNA probes from GKN1 or vector transfected AGS cells to the array, we could 


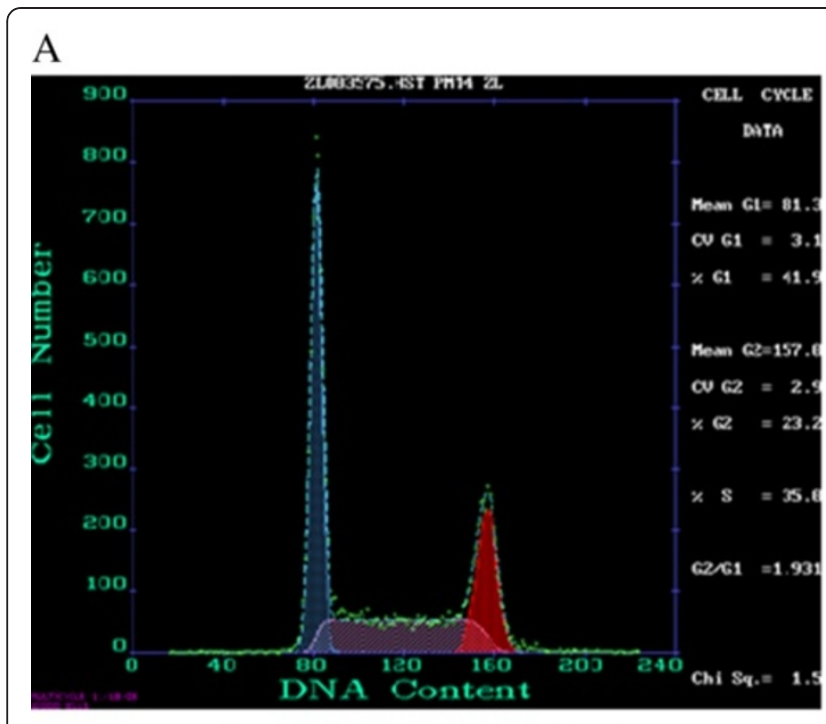

AGS cells with GKN1 transfection

B

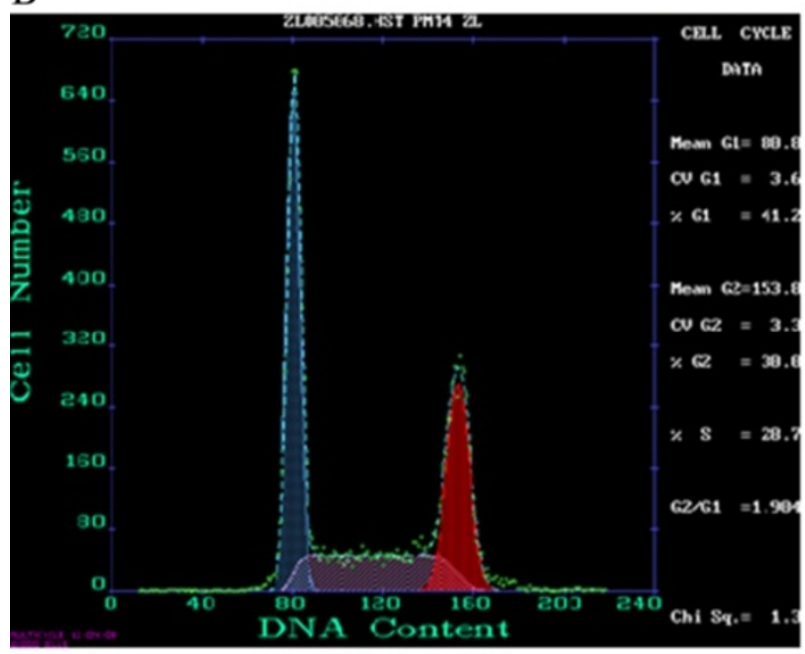

AGS cells with GKN1 transfection

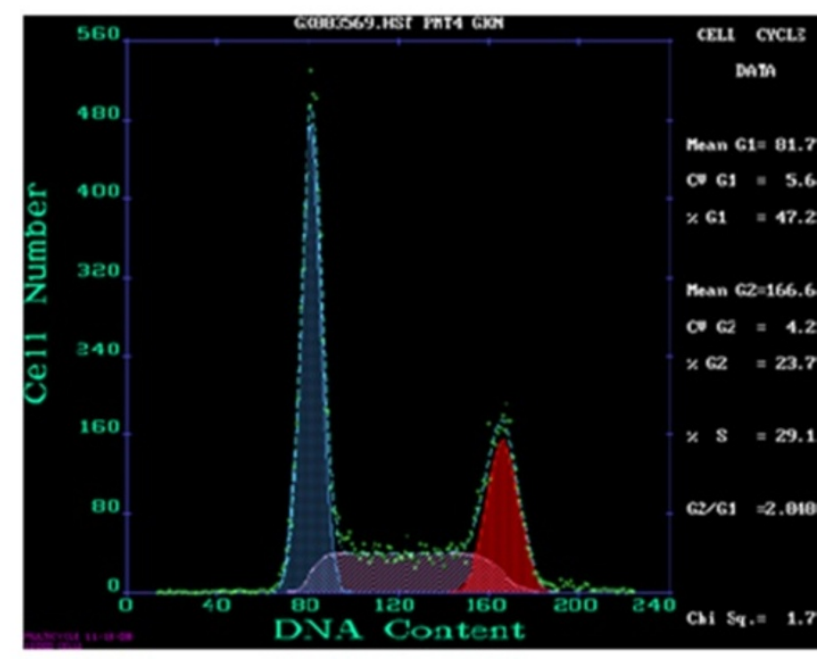

AGS cells with vector transfection

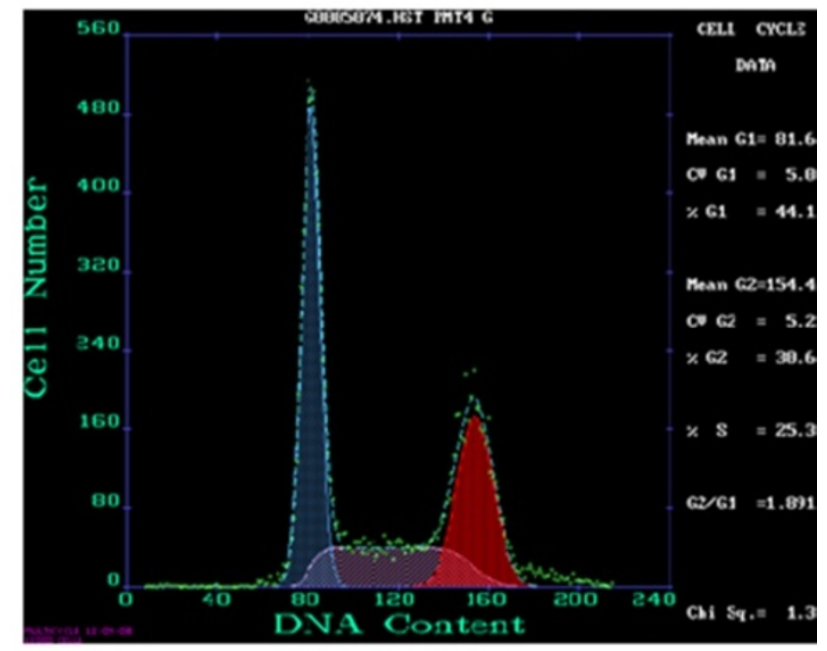

AGS cells with vector transfection

Figure $\mathbf{5}$ Effect of GKN1 on cell cycle re-distribution. The GKN1 or vector transfected AGS cells were arrested in the cell cycle with $1 \mathrm{~h}$ olomoucine treatment and continued to incubate for another $1 \mathrm{~h}$ without olomoucine. $\mathbf{A}$ : after $1 \mathrm{~h}$ olomoucine treatment; $\mathbf{B}$ : an additional hour incubation without olomoucine.

detect differential expression of these genes between GKN1 transfected and control cells. Specifically, a total of 16 genes were downregulated, and 3 genes were upregulated after restoration of GKN1 expression in AGS cells compared to the control cells (Table 4).

\section{Discussion}

In the current study, we investigated expression of GKN1 mRNA and protein in tissue specimens from normal gastric mucosa, atrophic gastritis, intestinal metaplasia, dysplastic lesions, and gastric cancer. We found that GKN1 expression was progressively downregulated and lost from precancerous to cancerous tissues, indicating that the loss of GKN1 expression may contribute to gastric carcinogenesis. Previous studies showed decreased GKN1 expression in gastric cancer [5,14]. Our current study, for the first time, demonstrated the progressive loss of GKN1 mRNA and protein from normal to precancerous and cancer tissue specimens, indicating the role of GKN1 in gastric cancer homeostasis and alteration of GKN1 expression in gastric cancer.

To further investigate the possible biological functions of GKN1 in gastric cancer, we successfully cloned and transfected GKN1 into gastric cancer AGS cells that do 

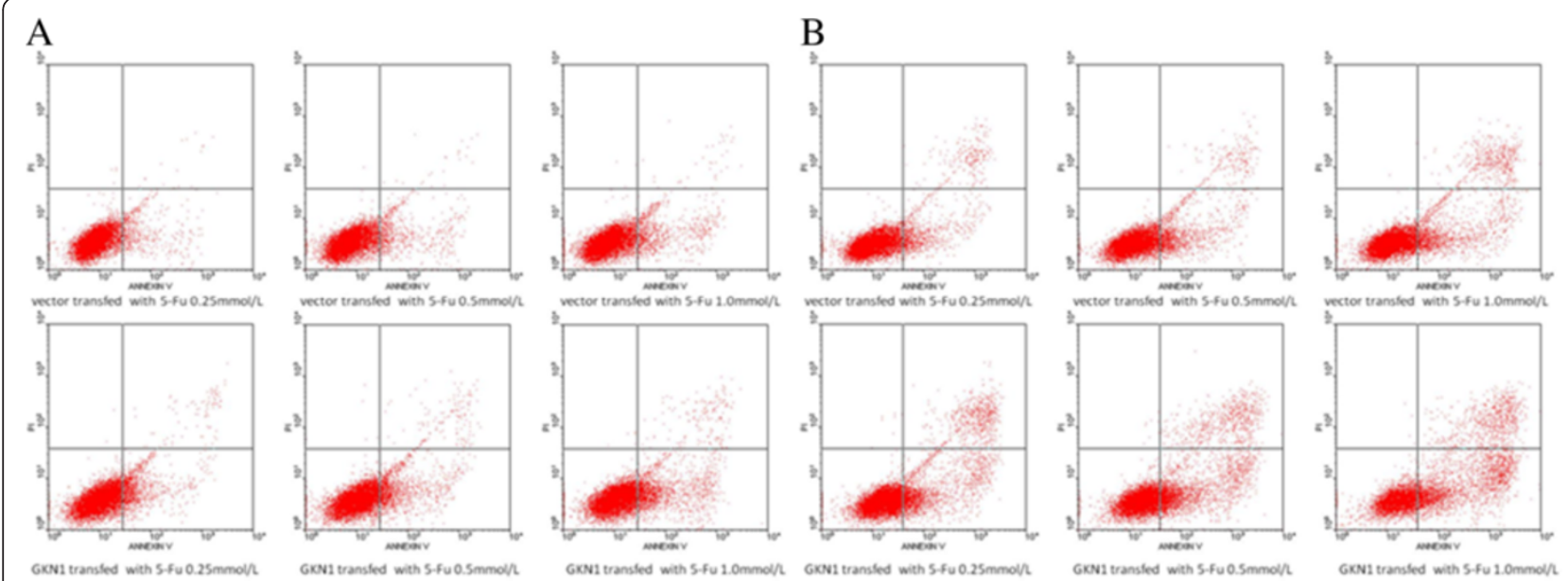

Figure 6 GKN1 enhanced tumor cell sensitivity to 5-FU-mediated apoptosis. The GKN1 or vector transfected gastric cancer cells were grown and treated with different doses of 5-Fu in 24 and $48 \mathrm{~h}$. After that, these cells were subjected to flow cytometry assay for apoptosis. A: 5-Fu treatment for $24 \mathrm{~h}$; B: 5-Fu treatment for $48 \mathrm{~h}$.

not express GKN1 protein. We found that restoration of GKN1 expression suppressed tumor cell viability and induced them to undergo apoptosis and enhanced effects of 5-FU on gastric cancer cells. These data indicate the role of GKN1 in gastric cancer and could be further developed as a novel target for control of gastric cancer.

The following data of flow cytometry and TUNEL assay showed that GKN1 may induce apoptosis in cancer cells. These data were consistent with the previous studies $[15,16]$. The regulation of cell cycle redistribution closely correlated with suppression of cancer cells. After GNK1 transfected, AGS cells were treated with olomoucine, a CDK inhibitor, to enrich cells at G1 phase of the cell cycle. But GKN1 was unable to hold cells in the G1-S transition phase, suggesting that GKN1 may not affect the cell cycle. Nevertheless, other studies found that overexpression of GKN1 resulted in cell cycle arrest at G1 phase [17] or G2/M phase of the cell cycles [18]. The reason for this discrepancy is unclear, but may be because that the exogenous GKN1 protein was not equal to the endogenous protein in regulation of cell phenotypes or functions. Our current study using the gene transfection technique demonstrated that induction of GKN1 expression induced apoptosis of gastric cancer

Table 3 5-FU induction of apoptosis in gastric cancer AGS cells

\begin{tabular}{llrrr}
\hline Group & $\begin{array}{l}\text { Time } \\
\text { (h) }\end{array}$ & \multicolumn{4}{c}{ 5-FU-induced apoptosis (\%) } \\
\cline { 3 - 5 } & & $\mathbf{0 . 2 5} \mathbf{~} \mathbf{m o l} / \mathbf{L}$ & $\mathbf{0 . 5} \mathbf{~ m m o l} / \mathbf{L}$ & $\mathbf{1 . 0} \mathbf{~ m m o l} / \mathbf{L}$ \\
\hline Vector transfected & 24 & $5.53 \pm 0.06$ & $7.70 \pm 0.10$ & $9.57 \pm 0.21$ \\
GKN1 transfected & 24 & $13.03 \pm 0.40$ & $14.93 \pm 0.15$ & $19.73 \pm 0.23$ \\
Vector transfected & 48 & $8.23 \pm 0.21$ & $12.33 \pm 0.21$ & $14.33 \pm 0.06$ \\
GKN1 transfected & 48 & $18.13 \pm 0.72$ & $23.30 \pm 0.79$ & $34.83 \pm 0.67$ \\
\hline
\end{tabular}

AGS cells. However, further studies are needed to explore this discrepancy.

Both the previous studies [5,9] and our current immunohistochemical data showed that the GKN1 protein was expressed in the top layers of gastric mucosa and glands, but was absent in the deeper layer of the mucosa and glands. This localization may contribute to the

Table 4 Changed expression of apoptosis-related genes in GKN1-transfected AGS cells

\begin{tabular}{lcr}
\hline Gene symbol & GenBank number & Fold change \\
\hline ABL1 & NM_005157 & 0.481 \\
APAF1 & NM_001160 & 0.489 \\
BAX & NM_004324 & 0.347 \\
BCL10 & NM_003921 & 0.465 \\
BCL2L1 & NM_138578 & 0.257 \\
BCLAF1 & NM_014739 & 0.497 \\
BOK & NM_032515 & 0.429 \\
CARD11 & NM_032415 & 0.181 \\
CIDEB & NM_014430 & 0.366 \\
NOL3 & NM_003946 & 0.219 \\
TNFRSF10C & NM_003841 & 0.365 \\
TNFRSF10D & NM_003840 & 0.259 \\
TNFRSF1A & NM_001065 & 0.358 \\
TNFRSF6B & NM_003823 & 0.465 \\
TP53BP2 & NM_005426 & 0.381 \\
TRAF3 & NM_003300 & 0.478 \\
BCL2A1 & NM_004049 & 2.036 \\
BCL2L11 & NM_006538 & 2.267 \\
CARD8 & NM_014959 & 2.589 \\
\hline
\end{tabular}


mitogenic and restitutional functions of GKN1 protein in maintenance of gastric mucosa homeostasis [19]. It is because the top layers of the epithelium are committed to apoptosis process in physiological condition. However, other studies suggested that GKN1 may be secreted from epithelial cells, and have functions in both paracrine and autocrine systems [6] in control of normal cell growth, differentiation, and apoptosis.

In addition, this study demonstrated that GKN1 was able to increase the sensitivity of gastric cancer cells to 5-FU treatment. This finding suggested that GKN1 may be useful as an adjuvant target in combination with other chemotherapeutical agents in the treatment of gastric cancer. 5-FU has been a widely used as a chemotherapeutic agent in treating patients with gastric cancer. It is a pyrimidine analogue and can incorporate into DNA or RNA for the induction of cell cycle arrest and apoptosis through inhibition of DNA duplication in tumor cells. In this regard, GKN1 could induce cell apoptosis, thus GKN1 could enhance 5-FU antitumor activity in gastric cancer cells. This result may partially explain the reason that patients who have lost GKN1 expression have shorter overall survival [20]. However, it remains to be determined how GKN1 is able to induce apoptosis in gastric cancer cells.

Our preliminary data revealed that GKN1 expression was able to modulate expression of several apoptosisrelated genes using a cDNA microarray analysis. Of the 112 genes covered by the Oligo GEArrays Human Apoptosis Microarray, the expression of 19 genes may directly affect by GKN1. However, some of these screening genes (such as BAX and BCL2A1) may be indirectly or even not affected or regulated by GKN1 protein [14,21]. Considering limitations of the microarray analysis, these screening genes need to be verified by qRT-PCR or western blot analyses in the further study.

\section{Conclusions}

In summary, expression of GKN1 mRNA and protein was progressively downregulated from the normal mucosa, precancerous to cancerous gastric tissues. Restoration of GKN1 expression induced gastric cancer cells to undergo apoptosis, and enhanced sensitivity to 5-FU-induced apoptosis. These data indicate that GKN1 plays a role in regulation of gastric epithelial homeostasis and that lost GKN1 expression could contribute to gastric cancer development.

\section{Abbreviations}

GKN1: Gastrokine-1; 5-FU: 5-fluorouracil.

\section{Competing interests}

The authors declare that they have no competing interests.

\section{Authors' contributions}

Mao W and Chen J performed the experiments and wrote the paper; Peng $\mathrm{TL}$ and Yin XF organized the figures and collected tissue specimens and patients' data; Chen MH designed this study and supervised the writing and discussion. All authors have read and approved the final version of this manuscript.

\section{Acknowledgements}

This study was supported in part by grants from The National Natural Science Foundation of China (No. 81072048 and No. 30871145), from the Natural Science Foundation of Guangdong Province (No. 7001641), from the Junior Teacher Cultivation Project of Sun Yat-sen University (No. 09ykpy22), and (No. 10ykjc23).

\section{Author details}

${ }^{1}$ Department of Gastroenterology, the First Affiliated Hospital of Sun Yat-Sen University, Guangzhou, China. ²Department of Gastroenterology, the Third Affiliated Hospital of Sun Yat-Sen University, Guangzhou, China. ${ }^{3}$ Digestive System Tissue Bank, the First Affiliated Hospital of Sun Yat-Sen University, Guangzhou, China.

Received: 9 March 2012 Accepted: 17 May 2012

Published: 23 May 2012

\section{References}

1. Talamonti MS, Kim SP, Yao KA, Wayne JD, Feinglass J, Bennett CL, Rao S: Surgical outcomes of patients with gastric carcinoma: the importance of primary tumor location and microvessel invasion. Surgery 2003, 134:720-727. discussion 727-729.

2. Jemal A, Thomas A, Murray T, Thun M: Cancer statistics, 2002. CA Cancer J Clin 2002, 52:23-47.

3. Krejs GJ: Gastric cancer: epidemiology and risk factors. Dig Dis 2010, 28:600-603.

4. Yoshikawa Y, Mukai H, Hino F, Asada K, Kato I: Isolation of two novel genes, down-regulated in gastric cancer. Jpn J Cancer Res 2000, 91:459-463.

5. Oien KA, McGregor F, Butler S, Ferrier RK, Downie I, Bryce S, Burns S, Keith WN: Gastrokine 1 is abundantly and specifically expressed in superficial gastric epithelium, down-regulated in gastric carcinoma, and shows high evolutionary conservation. J Pathol 2004, 203:789-797.

6. Martin TE, Powell CT, Wang Z, Bhattacharyya S, Walsh-Reitz MM, Agarwal K, Toback FG: A novel mitogenic protein that is highly expressed in cells of the gastric antrum mucosa. Am J Physiol Gastrointest Liver Physiol 2003, 285:G332-G343.

7. Walsh-Reitz MM, Huang EF, Musch MW, Chang EB, Martin TE, Kartha S, Toback FG: AMP-18 protects barrier function of colonic epithelial cells: role of tight junction proteins. Am J Physiol Gastrointest Liver Physiol 2005, 289:G163-G171.

8. Sanchez-Pulido L, Devos D, Valencia A: BRICHOS: a conserved domain in proteins associated with dementia, respiratory distress and cancer. Trends Biochem Sci 2002, 27:329-332.

9. Nardone G, Rippa E, Martin G, Rocco A, Siciliano RA, Fiengo A, Cacace G, Malorni A, Budillon G, Arcari P: Gastrokine 1 expression in patients with and without Helicobacter pylori infection. Dig Liver Dis 2007, 39:122-129.

10. Martin G, Wex T, Treiber G, Malfertheiner P, Nardone G: Low-dose aspirin reduces the gene expression of gastrokine- 1 in the antral mucosa of healthy subjects. Aliment Pharmacol Ther 2008, 28:782-788.

11. Nardone G, Martin G, Rocco A, Rippa E, La Monica G, Caruso F, Arcari P: Molecular expression of Gastrokine 1 in normal mucosa and in Helicobacter pylori-related preneoplastic and neoplastic gastric lesions. Cancer Biol Ther 2008, 7:1890-1895.

12. Khakoo SI, Lobo AJ, Shepherd NA, Wilkinson SP: Histological assessment of the Sydney classification of endoscopic gastritis. Gut 1994, 35:1172-1175.

13. Bossenmeyer-Pourie C, Kannan R, Ribieras S, Wendling C, Stoll I, Thim L, Tomasetto C, Rio MC: The trefoil factor 1 participates in gastrointestinal cell differentiation by delaying G1-S phase transition and reducing apoptosis. J Cell Biol 2002, 157:761-770.

14. Yoon JH, Song JH, Zhang C, Jin M, Kang YH, Nam SW, Lee JY, Park WS: Inactivation of the Gastrokine 1 gene in gastric adenomas and carcinomas. J Pathol 2011, 223:618-625. 
15. Rippa E, La Monica G, Allocca R, Romano MF, De Palma M, Arcari P: Overexpression of gastrokine 1 in gastric cancer cells induces Fas-mediated apoptosis. J Cell Physiol 2011, 226:2571-2578.

16. Yoon JH, Kang YH, Choi YJ, Park IS, Nam SW, Lee JY, Lee YS, Park WS: Gastrokine 1 functions as a tumor suppressor by inhibition of epithelial-mesenchymal transition in gastric cancers. J Cancer Res Clin Oncol 2011, 137:1697-1704.

17. Xing R, Li W, Cui J, Zhang J, Kang B, Wang Y, Wang Z, Liu S, Lu Y. Gastrokine 1 induces senescence through p16/Rb pathway activation in gastric cancer cells. Gut 2012, 61:43-52.

18. Yan GR, Xu SH, Tan ZL, Yin XF, He QY: Proteomics characterization of gastrokine 1-induced growth inhibition of gastric cancer cells. Proteomics 2011, 11:3657-3664

19. Toback FG, Walsh-Reitz MM, Musch MW, Chang EB, Del Valle J, Ren H, Huang E, Martin TE: Peptide fragments of AMP-18, a novel secreted gastric antrum mucosal protein, are mitogenic and motogenic. Am J Physiol Gastrointest Liver Physiol 2003, 285:G344-G353.

20. Moss SF, Lee JW, Sabo E, Rubin AK, Rommel J, Westley BR, May FE, Gao J, Meitner PA, Tavares R, Resnick MB: Decreased expression of gastrokine 1 and the trefoil factor interacting protein TFIZ1/GKN2 in gastric cancer: influence of tumor histology and relationship to prognosis. Clin Cancer Res 2008, 14:4161-4167.

21. Vogler M: BCL2A1: the underdog in the BCL2 family. Cell Death Differ 2012, 19:67-74

doi:10.1186/1756-9966-31-49

Cite this article as: Mao et al:: Downregulation of gastrokine- 1 in gastric cancer tissues and restoration of its expression induced gastric cancer cells to apoptosis. Journal of Experimental \& Clinical Cancer Research 2012 31:49.

\section{Submit your next manuscript to BioMed Central and take full advantage of:}

- Convenient online submission

- Thorough peer review

- No space constraints or color figure charges

- Immediate publication on acceptance

- Inclusion in PubMed, CAS, Scopus and Google Scholar

- Research which is freely available for redistribution 